\title{
Torsion of cystic ovary: an unusual cause of acute abdomen in midtrimester pregnancy
}

\author{
Poornima C*, Devi B, Seetha Panicker
}

\begin{abstract}
Department of Obstetrics \& Gynecology, PSG Institute of Medical Sciences \& Research, Coimbatore-641004, Tamil
\end{abstract} Nadu, India

Received: 22 September 2014

Accepted: 10 October 2014

\author{
*Correspondence: \\ Dr. Poornima C, \\ E-mail: poornimatolstoy@ rediffmail.com
}

Copyright: $\odot$ the author(s), publisher and licensee Medip Academy. This is an open-access article distributed under the terms of the Creative Commons Attribution Non-Commercial License, which permits unrestricted non-commercial use, distribution, and reproduction in any medium, provided the original work is properly cited.

\begin{abstract}
Torsion of ovary is an infrequent cause of surgical emergency in pregnancy. Most frequently ovarian torsion occurs in first trimester, occasionally in second and rarely in the third trimester. Diagnosis of ovarian torsion is challenging due to non-specific clinical features. We report here a case of dermoid cyst causing ovarian torsion in second trimester and imaging modalities for its diagnosis and management. A case of 19 year old primi at 24 weeks of gestational age came with complaints of pain in right iliac fossa for 2 days. USG done showed non vascular heterogeneous hyper echoic lesion in right adnexa, suggestive of torsion of right ovary with viable intrauterine fetus. She underwent emergency laparotomy, during which we removed necrotic and gangrenous right ovary and fallopian tube. Ovarian torsion is an infrequent cause of abdominal pain in pregnancy. Though it occurs most frequently in first trimester, it may occur in second trimester also. USG is an accurate tool in diagnosing torsion. Early surgical management is associated with favorable maternal and fetal outcome.
\end{abstract}

Keywords: Abdominal pain, Torsion, Ovary, Pregnancy

\section{INTRODUCTION}

Ovarian torsion is the fifth most common gynecologic surgical emergency; with prevalence rate of $2.7 \%$ to $3 \% .^{1-2}$ Pregnant women have a greater risk of torsion of the adnexa than non-pregnant women. Approximately $20 \%$ of the cases occur during pregnancy. ${ }^{3}$ Torsion occurs for two main reasons: hyper mobility of the ovary and adnexal lesion. ${ }^{4}$ The majority of adnexal masses in pregnancy are benign. Mature teratomas, or dermoids, are the most common ovarian tumor in pregnancy, comprising up to $44 \%$ of all ovarian neoplasms. ${ }^{5}$ Of patients who require surgical management of adnexal masses in pregnancy, torsion is the most common acute complication with an incidence of 5 to $44 \% .^{6}$ Although torsion is more common in the first trimester, when the gravid uterus is expanding most rapidly, cases of outside first trimester have been reported. ${ }^{7}$

\section{CASE REPORT}

A 19 year old primigravida presented at 25 weeks of gestation, with sudden onset of pain in the right iliac fossa. There was no history of urinary disturbances (or) bowl disturbances. Her conception was spontaneous. Till now her antenatal period was uneventful. On examination, she was afebrile, vitals stable, uterus was relaxed corresponding to 24 weeks of gestation, and FHR was normal, severe tenderness and guarding in right iliac fossa. Per speculum cervical os was closed. Her blood and urine investigations were within normal limits. Clinically we suspected acute appendicitis. In sonography right adnexa showed well defined heterogeneous lesion of $5.8 \times 4.2 \mathrm{~cm}$ with internal anechoic area and with minimal free fluid surrounding it. No internal vascularity with color Doppler. Left ovary visualized normally. Other abdominal organs found to be normal. Grey scale features and color Doppler suggested right adnexal 
torsion (Figure 1). Hence she was planned for emergency laparotomy after duly explaining the risk of surgery. Operation details: Right ovary and fallopian tube enlarged to $5 \mathrm{~cm}$, undergone torsion thrice and appeared necrotic and gangrenous. Right salpingo-oophorectomy done (Figure 2). Post operatively she had uneventful recovery and she was started on progesterone's. Histopathology consistent with features of torsion and dermoid cyst.

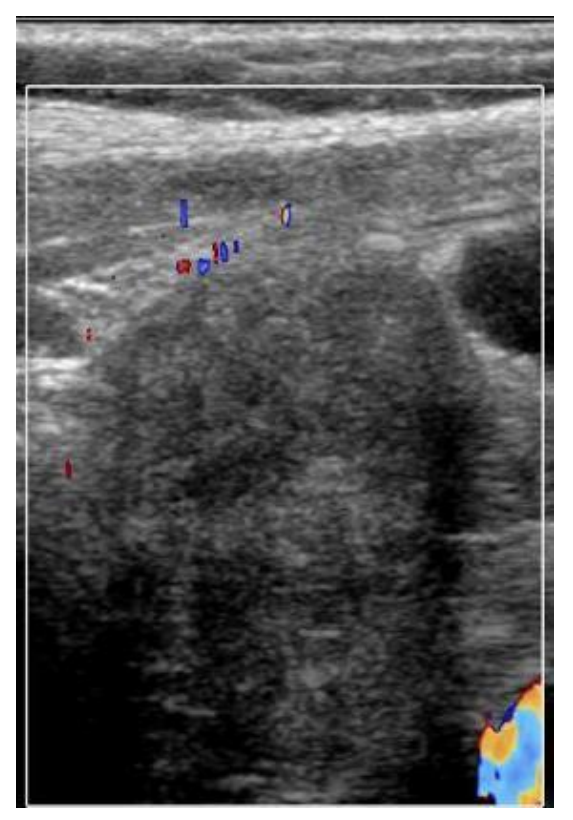

Figure 1: Ultrasound Doppler image of right adnexa.

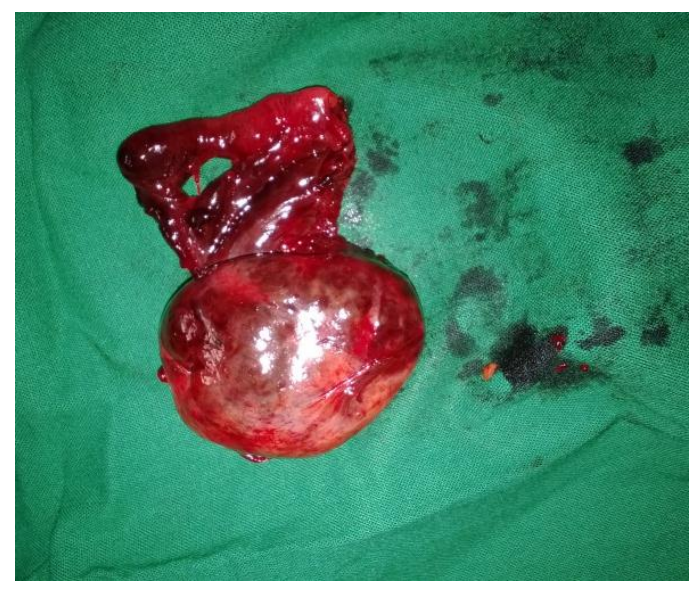

Figure 2: Right salpingo-oophorectomy specimen.

\section{DISCUSSION}

Adnexal torsion is an uncommon cause of acute abdomen in second trimester. Diagnosis of acute abdomen in second trimester is difficult, because gravid uterus may hide classical signs. Peritoneal signs may be absent due to lifting of the abdominal wall. ${ }^{8}$ Clinical features of ovarian torsion mimics other conditions causing acute abdomen in pregnancy. Most common symptoms are pain abdomen, nausea and vomiting.
Study conducted by Shoenn-dhy Cahng et al.: surgical intervention for maternal ovarian torsion in pregnancy showed. The most common symptoms and signs were pelvic pain $(95 \%)$ and an adnexal or pelvic mass $(95 \%)$, followed by nausea and vomiting $(65 \%)$, elevated WBC $>12 \times 10^{9} / \mathrm{L}(45 \%)$ and fever (10\%). This study also concluded the diagnosis of ovarian torsion is often missed due to non-specific clinical features and uncommon objective findings. ${ }^{9}$

Clinical differential diagnosis of adnexal torsion includes appendicitis, diverticulitis, UTI, renal stones, bowel obstruction. Acute appendicitis is the most common incorrect diagnosis.

Ultrasound is the first choice imaging modality used for the evaluation of patients with acute abdomen in pregnancy. However, in the second and third trimester, it is sometimes difficult to visualize the ovaries as they are displaced from the pelvis by the gravid uterus.

An enlarged, heterogeneous appearing ovary is the most common ultrasound finding ${ }^{10}$; however the presence of normal appearing ovaries does not rule out the diagnosis.

Various other sonographic features associated with ovarian torsion include:

- $\quad$ Presences of peripheral follicles

- Free fluid in the pouch of Douglas

- Twisted pedicle leading to, whirlpool sign (uncommon)

- Asymmetric thickening of ovarian wall cysts

In our case she had only acute pain in the right flank and Ultra sound showed common features of ovarian torsion.

Reuven Mashiach, MD, Nir Melamed, MD, et al. Study results showed sonographic diagnosis of ovarian torsion had overall accuracy of $74.6 \%$. Abnormal ovarian blood flow and the presence of free fluid were the most diagnostically accurate isolated sonographic signs of ovarian torsion. Combinations of sonographic signs had higher specificity and positive predictive values for ovarian torsion. The absence of typical sonographic signs does not rule out ovarian torsion, especially when the clinical presentation is suggestive. ${ }^{12}$

Lee et al. concluded that identification of the twisted vascular pedicle through ultrasonography is suggestive of ovarian torsion, and color Doppler sonography could be helpful in predicting the viability of adnexal structures by depicting blood flow with in the twisted vascular pedicle. $^{13}$

Ovarian torsion will affect venous outflow early and the arterial flow later. Due to the venous out flow, the 
affected ovary typically enlarged and become edematous leading to greater resistance.

In a study by Rosado et al., all three cases of ovarian torsion demonstrated arterial flow. They postulated two possible explanations: (a) venous thrombosis due to torsion leads to symptoms and ovarian necrosis before arterial thrombosis occurs and (b) persistent adnexal arterial flow is related to the dual ovarian blood supply. One branch derived from the adnexal branch of the uterine artery and one as a branch directly from the aorta. $^{14}$

A strange venous or arterial flow on ultra sound is a good warning of torsion; it indicates that the possibility is there. However; a positive flow of Doppler does not necessarily mean torsion is not present. ${ }^{15}$

The combination of Doppler flow imaging and morphologic ultra sound assessment of the twisted mass may improve diagnostic accuracy. ${ }^{16}$

CT \& MRI may also be useful if ultrasound findings are ambiguous or if the lesion is not well depicted sonographically.

CT \& MRI imaging features of adnexal torsion included fallopian tube thickening, smooth wall thickening of the twisted adnexal cystic mass, acsities \& uterine deviation to the twisted side. ${ }^{17}$

MRI can be safely used in pregnancy to evaluate tissue composition \& to differentiate ovarian mass from other abdominal mass. Ultrasound for ovarian mass evaluation is technically difficult in third trimester; hence MRI is especially useful for third trimester imaging. ${ }^{18}$

Immediate surgery is the treatment for suspected ovarian torsion. Studies have shown that surgery for adnexal masses during pregnancy is associated with an increased risk of spontaneous abortion, preterm labor, fetal growth restriction, and neonatal death. ${ }^{6,19,20}$ Risk of preterm labour is more during third trimester. In one study preterm labour occurred in $26 \%$ of women had surgery during the second trimester and in $82 \%$ of those who had surgery during the third trimester. ${ }^{21}$

Mathevet P, et al. concluded Laparoscopic management of adnexal masses in pregnancy by an experienced team, is a safe and effective procedure that allows, compared to the traditional surgery, a shorter hospital stay, a reduced rate of post-operative complications and a decreased maternal and fetal morbidity. ${ }^{22}$

The safety of laparoscopy for adnexal masses in pregnancy has been demonstrated in several studies. ${ }^{22-24}$

\section{CONCLUSION}

Ovarian torsion is an infrequent cause of acute abdominal pain in pregnancy. Though it occurs most frequently in first trimester, it may occur in second trimester also. Diagnosis needs high clinical suspicion and radiological examination. Still USG is an accurate tool in diagnosing torsion ovary. Color Doppler improves the diagnostic accuracy. The CT \& MRI may also be useful if ultrasound findings are inconsistent. Early surgical management is associated with favorable maternal and fetal outcome.

\section{Funding: No funding sources \\ Conflict of interest: None declared \\ Ethical approval: Not required}

\section{REFERENCES}

1. Hibbard LT. Adnexal torsion. Am J Obstet Gynecol. 1985;152:456-61.

2. Bayer AI, Wiskind AK. Adnexal torsion: can the adnexa be saved? Am J Obstet Gynecol. 1994;171:1506-11.

3. Bider D, Mashiach S, Dulitzky M, Kokia E, Lipitz S, Ben-Rafael Z. Clinical, surgical and pathologic findings of adnexal torsion in pregnant and nonpregnant women. Surg Gynecol Obstet. 1991;173(5):363-6.

4. Dahnert W. Ovarian torsion. In: Dahnert W, eds. Radiology Review Manual. 5th ed. New Zealand: Hubsta Ltd.; 2007.

5. Koonings PP, Campbell K, Mishell DR Jr, Grimes DA. Relative frequency of primary ovarian neoplasms: a 10-year review. Obstet Gynecol. 1989;74:921-6.

6. Whitecar MP, Turner S, Higby MK. Adnexal masses in pregnancy: a review of 130 cases undergoing surgical management. Am J Obstet Gynecol. 1999;181:19-24.

7. Bromley B, Benacerraf B. Adnexal masses during pregnancy: accuracy of sonographic diagnosis and outcome. J Ultrasound Med. 1997;16:447-52, 362-3.

8. Taylor D, Smith CV, Perry RL, Lifford KL, Talavera F. Acute abdomen and pregnancy, 2009. Available at: http://emedicine.medscape.com/article/195976overview. Accessed 28 March 2014.

9. Chang SD, Yen CF, Lo LM, Lee CL, Liang CC. Surgical intervention for maternal ovarian torsion in pregnancy. Taiwan J Obstet Gynecol. 2011 Dec;50(4):458-62.

10. Servaes S, Zurakowski D, Laufer MR, Feins N, Chow JS. Sonographic findings of ovarian torsion in children. Pediatr Radiol. 2007;37(5):446-51.

11. Ben-Ami M, Prelitz Y, Haddad S. The effectiveness of spectral and color Doppler in predicting ovarian torsion: a prospective study. Eur J Obstet Gynecol Reprod Biol. 2002 Aug;104(1):64-6.

12. Mashiach R, Melamed N, Gilad N, Ben-Shitrit G, Meizner I. Sonographic diagnosis of ovarian torsion. Accuracy and predictive factors. J Ultrasound Med. 2011;30:1205-10.

13. Lee EJ, Kwen HG, Joo HJ, Suh JH, Fleischer AC. Diagnosis of ovarian torsion with color Doppler 
sonography: depiction of twisted vascular pedicle. J Ultrasound Med. 1998 Feb;17(2):83-9.

14. Rosado WM, Trambert MA, Gosink BB, Pretorius DH. Adnexal torsion: Diagnosis by using Doppler sonography. AJR Am J Roentgenol. 1992;159:12513.

15. Martin C, Magee K. Ovarian torsion in a 20 year old patient. Can J Emerg Med. 2006;8(2):126-9.

16. Ujwala Parashar, Talat Uppal. Ovarian torsion: an overview. Autumn (Pain). 2011;13(1):34-5.

17. Rha SE, Byun JY, Jung SE, Jung JI, Choi BG, Kim BS, et al. CT and MRI imaging features of adnexal torsion. Radiographics. 2002 Mar-Apr;22(2):283-94.

18. Sherer DM, Maitland CY, Levine NF, Eisenberg C, Abulafia O. Prenatal magnetic resonance imaging assisting in differentiating between large degenerating intramural leiomyoma \& complex adnexal mass during pregnancy. J Matern Fetal Med. 2000;9(3):186-9.

19. Platek DN, Henderson CE, Goldberg GL. The management of persistent adnexal masses in pregnancy. Am J Obstet Gynecol. 1995;173:123640.
20. Sayar H, Lhomme C, Verschraegen CF. Malignant adnexal masses in pregnancy. Obstet Gynecol Clin N Am. 2005;32:569-93.

21. Visser BC, Glasgow RE, Mulvihill KK, Mulvihill SJ. Safety \& timing of non-obstetrics abdominal surgery in pregnancy. Dig Surg. 2001;18:409-17.

22. Mathevet P, Nessah K, Dargent D, Mellier G. Laparoscopic management of adnexal masses in pregnancy; a case series. Eur J Obstet Gynecol Reprod Biol. 2003 Jun;108(2):217-22.

23. Moore RD, Smith WG. Laparoscopic management of adnexal masses in pregnant women. J Reprod Med. 1999;44:97-100.

24. Yuen PM, Ng PS, Leung PL, Rogers MS. Outcome in laparoscopic management of persistent adnexal mass during the second trimester of pregnancy. Surg Endosc. 2004;18:1354-7.

DOI: $10.5455 / 2320-1770.1 j r \operatorname{cog} 20141255$

Cite this article as: Poornima C, Devi B, Panicker

S. Torsion of cystic ovary: an unusual cause of acute abdomen in midtrimester pregnancy. Int J Reprod Contracept Obstet Gynecol 2014;3:1134-7. 